\title{
Dielectric Strength of Transformer Oil of Various Qualities
}

\author{
G. Rallis ${ }^{1}$, R. Sarathi ${ }^{2}$ and M. G. Danikas ${ }^{1, *}$ \\ ${ }^{I}$ Democritus University of Thrace, Department of Electrical and Computer Engineering, Electric Power Systems Laboratory, Xanthi, \\ Greece, 67100 \\ ${ }^{2}$ Indian Institute of Technology Madras, Department of Electrical Engineering, Chennai, India
}

Received 29 January 2021; Accepted 31 March 2021

\begin{abstract}
This paper focuses on the effects of dielectric strength on transformer oil reliability and on a reproduction of a voltage breakdown simulation during a dielectric strength test. A typical Foster test cell was used in order to measure the dielectric strength of a variety of oils. For a more complete picture, it requires the identification of more parameters but this paper examines only the above one as a result of the operation of a testing apparatus. It is shown that FEM/FDM analysis provides same information for the electrode gap. Bruce electrode provides highly uniform electric field. Factors such as voltage rate, relaxation time between measurements as well as the shape of the testing electrodes influences the dielectric strength of the liquid.
\end{abstract}

Keywords: breakdown, insulating oil, transformer oil, dielectric strength, simulation, circuit

\section{Introduction}

Mineral oils are used in the transformers insulating and cooling media. The inspection of the oil properties, based on established standards, is one of the most important criteria for assessing the status of the transformer. A most important property of transformer oil is its dielectric strength, a property that - among others - determines the longevity of transformers.

Physicochemical properties of mineral oils are the following: color, density, thermal expansion coefficient, specific heat capacity, thermal conductivity coefficient, viscosity, flow point, clarity, water solubility, gas solubility, evaporation, flash point and fire point, ash content, acidity, alkalinity and surface tension. In addition among the electrical properties are the dielectric strength, the power factor, the specific resistance and the relative permittivity $[1,2]$.

The insulant used in transformers should have good electrical, chemical and physical properties. It should have high dielectric strength with high specific resistance and low dielectric loss. The water content, acidity, sludge content should be low. In addition, the interfacial tension, viscosity, flash point, pour point should be considered depending on the zone of operation.

\section{Breakdown Mechanisms}

Breakdown mechanisms of transformer oil are distinguished in the following four types:

\section{A. Electronic Breakdown}

This mechanism concerns oils that are not mixtures and are clean, ie the moisture has been removed and they do not have

*E-mail address: mdanikas@ee.duth.gr

ISSN: 1791-2377 @ 2021 School of Science, IHU. All rights reserved.

doi:10.25103/jestr.141.24 suspended particles. This theory is relevant to streamer mechanism. The electrons emitted by cathode and those which are pre-existed in the liquid, under the influence of the electric field are accelerated to the anode acquiring kinetic energy. From their collision with the molecules of the liquid they cause their ionization. Because of the less mass of electrons compared to positive ions, they move faster creating a pile on the head of which there are electrons but on the tail accumulate positive ions. By cumulative process, electrons produce more piles faster and faster resulting in an increased conductivity, which eventually leads to the breakdown of the insulating oil at some value of the applied electric field.

\section{B. Breakdown due to Suspended Particles}

Dust particles, fibers, metal particles and particles from solid insulation are present in the liquid; by applying an electric field, they aforementioned foreign particles are polarized (because they have a higher relative permittivity than the insulating liquid) and are subjected to a force that pushes them to areas of greater field strength by the following equation:

$F=r^{3} \frac{\left(\varepsilon_{2}-\varepsilon_{1}\right)}{2\left(2 \varepsilon_{1}+\varepsilon_{2}\right)} \nabla E^{2}$

where,

$r$ : spherical electrode radius, $\varepsilon_{1}$ : relative permittivity of insulating oil, $\varepsilon_{2}$ : relative permittivity of the particle, $E$ : applied electric field.

The polarized particles form a conductive chain and they bridge the gap from one electrode to the other. These bridges are more conductive than their surrounding environment, resulting thus in a flow of electricity through these bridges, rendering local heating possible and causing and the electrical breakdown of the transformer oil. 


\section{Thermal}

Air or gas bubbles can exist in the insulating liquid and they can come from decomposition of the liquid molecules, from temperature and pressure changes, from gas pockets on the surface of the electrodes or from evaporation of the liquid due to the electrons emission from some micro-protrusions which are located on the surface of the electrodes due to on-site heterogeneity. As a result of the applied electric field E, bubbles can elongate along the gap forming chains - without necessarily - changing their volume creating a conductive path between the two electrodes. Then, ionization begins and the insulating liquid breakdown occurs. The developing electric field inside an air bubble $E_{b}(\varepsilon=$ permittivity of the oil) is:

$E_{b}=\frac{3 \varepsilon E}{2 \varepsilon+1}$

\section{Electro-transport and Electro-hydrodynamic Theory} In this case, the dielectric fluid has a high purity index, subjected to high voltage and under a stationary condition, electrical conduction will result from charges injected from the surface of the electrodes. The electrostatic Coulomb forces caused by the resulting space charge may lead to hydrodynamic instability which in turn produces current [3$6]$.

\section{Factors that Affect the Dielectric Strength}

Dielectric strength is a most important factor affecting the oil quality. Additional factors that affect dielectric strength are moisture, temperature, foreign particles and liquid movement, electrode material and pretreatment of the electrodes, geometry of the electrodes, size of the electrodes, oil sample volume, flow electrification due to its flow rate associated with the materials in the transformer, oil temperature, oil sample preparation, magnitude of applied voltage as well as its frequency, duration and polarity, molecular structure of the oil, its aromatic component, pressure, intervals between breakdowns, additives that may improve the oil behavior (antioxidants and metal deactivators) and the testing technique (including possible conditioning) [7].

\section{Experimental Setup}

The testing apparatus which used in the experiment can ascertain the effects of the gap, the voltage increase rate, the electrode type and the time between breakdowns to the voltage breakdown (Fig.1). Three types of transformer oil were used and compared. The oils have been checked in 2009, 2012 and 2015. Oil N1A (with the following characteristics: density $0.88 \mathrm{~g} / \mathrm{cm}^{3}$, mean breakdown voltage in $200983.9 \mathrm{kV}$, in $201285.6 \mathrm{kV}$ and in $201574.2 \mathrm{kV}$, humidity in 200916.6 ppm, in $201212.8 \mathrm{ppm}$ and in $201514.4 \mathrm{ppm}$, interfacial tension 17.3 dynes $/ \mathrm{cm}, \tan \delta 0.0706$, specific resistance $(\rho)$ $2.16 \mathrm{G} \Omega \mathrm{m}$, acidity $0.08 \mathrm{mgKOH} / \mathrm{g}$ ), oil N2B (density 0.865 $\mathrm{g} / \mathrm{cm}^{3}$, mean breakdown voltage in $200989 \mathrm{kV}$, in 201282.8 $\mathrm{kV}$ and in $201552.3 \mathrm{kV}$, humidity in $200911.6 \mathrm{ppm}$, in 2012 $5.7 \mathrm{ppm}$ and in $201512.8 \mathrm{ppm}$, interfacial tension 23.5 dynes $/ \mathrm{cm}, \tan \delta 0.0189$, specific resistance $(\rho) 16.35 \mathrm{G} \Omega \mathrm{m}$, acidity $0.04 \mathrm{mgKOH} / \mathrm{g}$ ) and oil N3A (density $0.865 \mathrm{~g} / \mathrm{cm}^{3}$, mean breakdown voltage in $200977.2 \mathrm{kV}$, in $201271.9 \mathrm{kV}$ and in $201580.7 \mathrm{kV}$, humidity in $200910.8 \mathrm{ppm}$, in 20128 ppm and in $201511 \mathrm{ppm}$, interfacial tension $28.1 \mathrm{dynes} / \mathrm{cm}$, $\tan \delta 0.0115$, specific resistance $(\rho) 2.11 \mathrm{G} \Omega \mathrm{m}$, acidity 0.03 $\mathrm{mgKOH} / \mathrm{g}$ ). All the oils were supplied by the Public Power
Corporation of Greece (from the area of Neo Faliro, near Athens) and were taken from transformers $150 \mathrm{kV} / 20 \mathrm{kV}$. The transformer with the oil N1A was subjected to major repair back in 1996, whereas the transformer with the oil N2B was checked for oil resistance in 2007 and the transformer with the oil N3A was also checked for oil resistance in 2008.
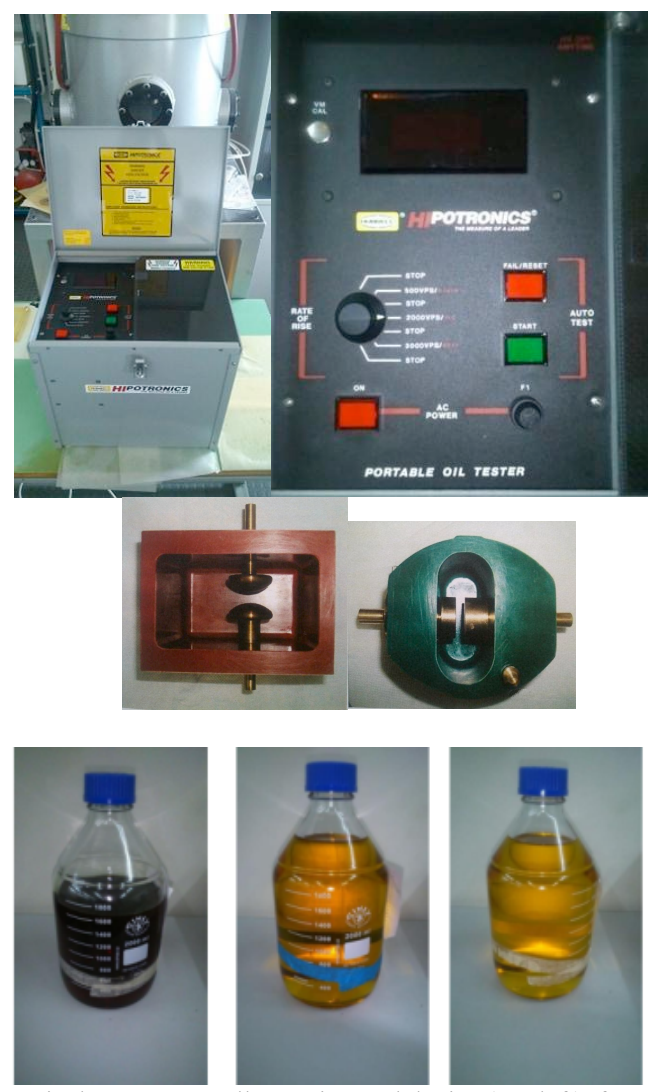

Fig. 1. Typical Foster test cell experimental device (up -left), front picture (up - middle), testing cells with adjustable gap (middle - left) Bruce profile on uppers and flat on bottom). Rate selections were $500 \mathrm{Vps}$, $2000 \mathrm{Vps}$ and $3000 \mathrm{Vps}$. The characteristics of the three oils (at the bottom, N1A, N2B, N3A) are described in the text. [Shots where taken from the lab]

\section{Testing procedure}

A typical Foster test cell was used for all experiments. Care was taken in order to follow the instructions and precautions of the relevant specifications for dielectric strength measurements of transformer oil. Testing has been performed with two pairs of electrodes, one with flat electrodes and the other with the typical Bruce profile electrodes (which also give a quasi-uniform electric field distribution). The various electrode gaps were set with the aid of clean feeler gauges. The tests were carried out as per IEC 60156-1995 standard [8].

For the work purposes the gaps which used where 2.55/2/1.8/1.5/1.25/1/0.8/0.5 mm. For each gap were taken 6 measurements for each increase voltage rate of $500 / 2500 / 3000 \mathrm{Vps}$. The relaxation time between gap changes was $1 \mathrm{~min}$ and between voltage rate changes was 5 mins. Initially, it was used the first cell and were taken all the series of measurements for all three, oils then the test was repeated for the next cell. After the assortment of all the results the dielectric strength $\mathrm{E}$ was given - since we had uniform gaps by the following equation, where $d$ is the gap, and $\mathrm{V}$ the applied voltage:

$E=\frac{V}{d}$ 
In all the following graphs the blue line represents 500 Vps, the red line represents $2000 \mathrm{Vps}$ and the green line represents 3000 Vps (Figs. 2 and 3)
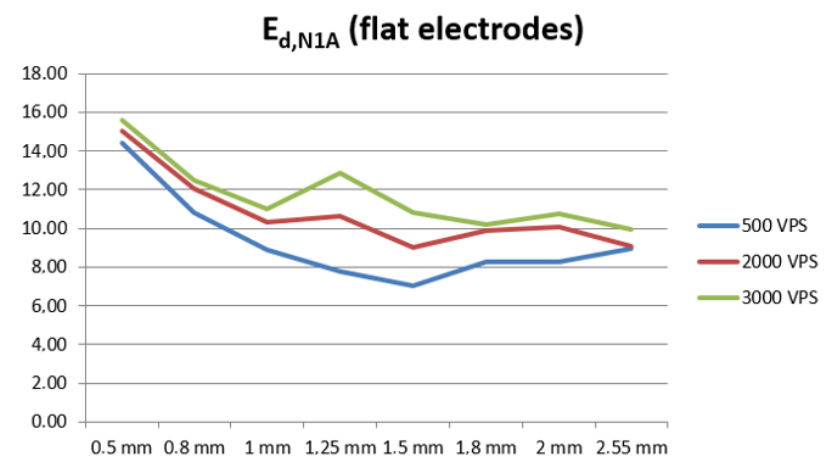

$E_{\mathrm{d}, \mathrm{N} 2 \mathrm{~B}}$ (flat electrodes)

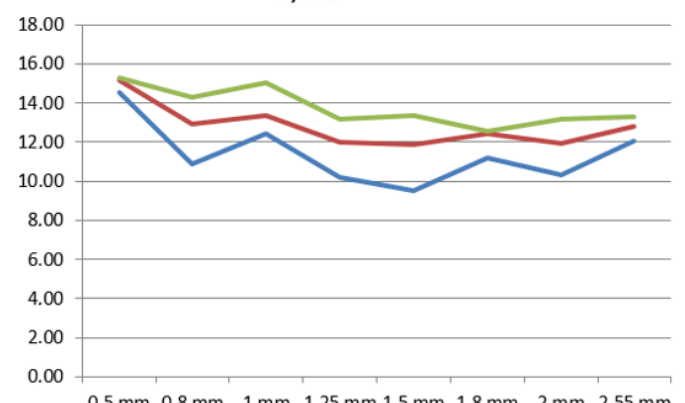

$E_{d, N 3 A}$ (flat electrodes)

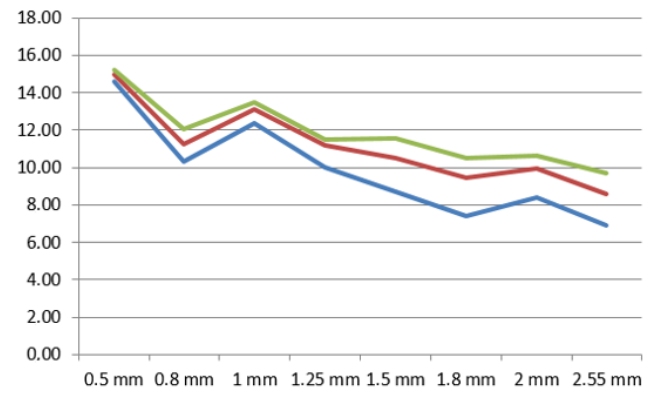

$E_{d, N 1 A}$ (bruce profile)

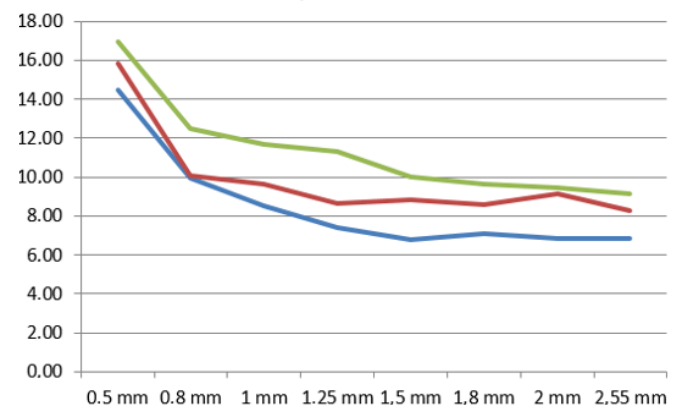

$E_{d, N 2 B}$ (bruce profile)

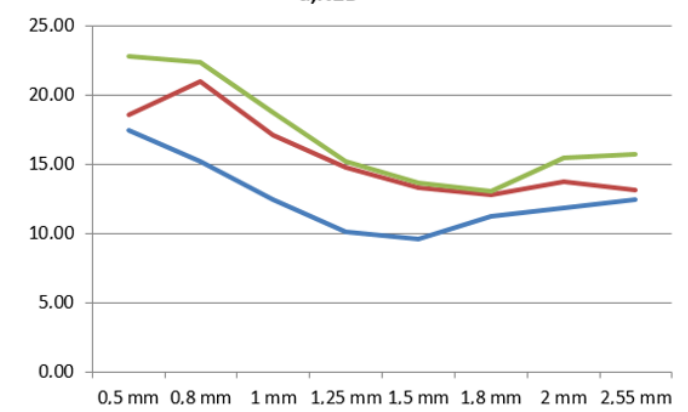

$E_{d, N 3 A}$ (bruce profile)

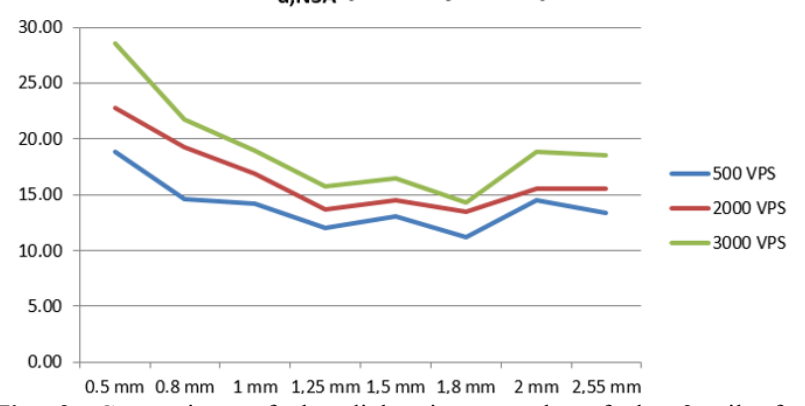

Fig. 2. Comparison of the dielectric strengths of the 3 oils for $500 / 2000 / 3000$ Vps with respect to $0.5 / 0.8 / 1 / 1.25 / 1.5 / 1.8 / 2 / 2.55 \mathrm{~mm}$ gap for flat electrodes and Bruce profile type (mushroom electrodes).

$E_{d, 500 \text { vPs }}$ (flat electrodes)
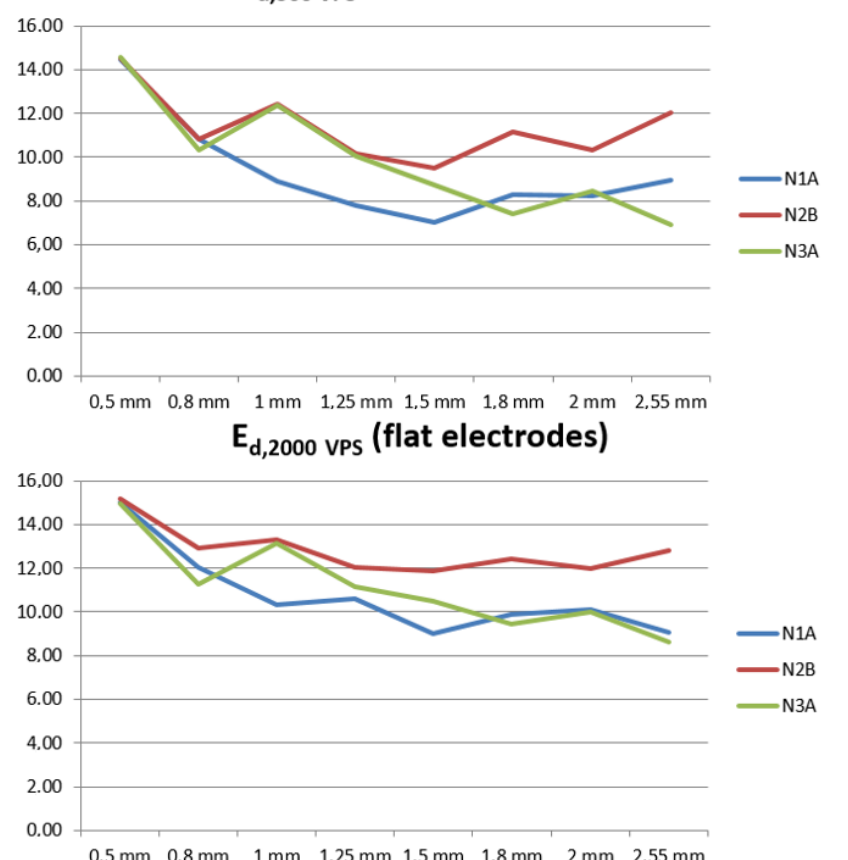

$E_{d, 3000 \text { vPs }}$ (flat electrodes)
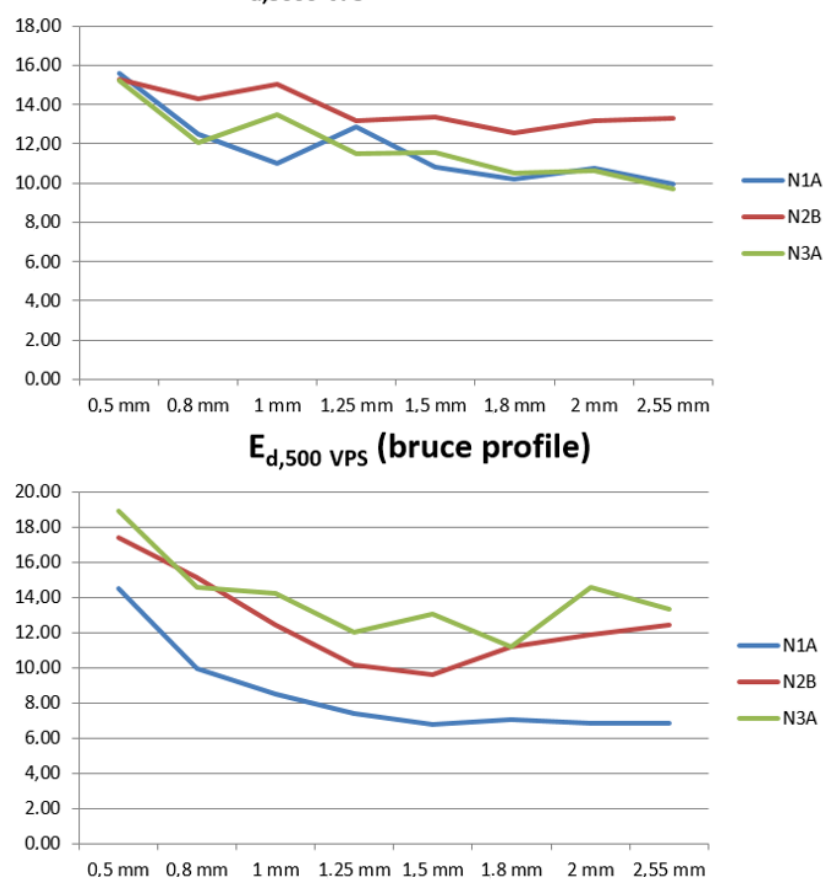
$E_{d, 2000 \text { vps }}$ (bruce profile)

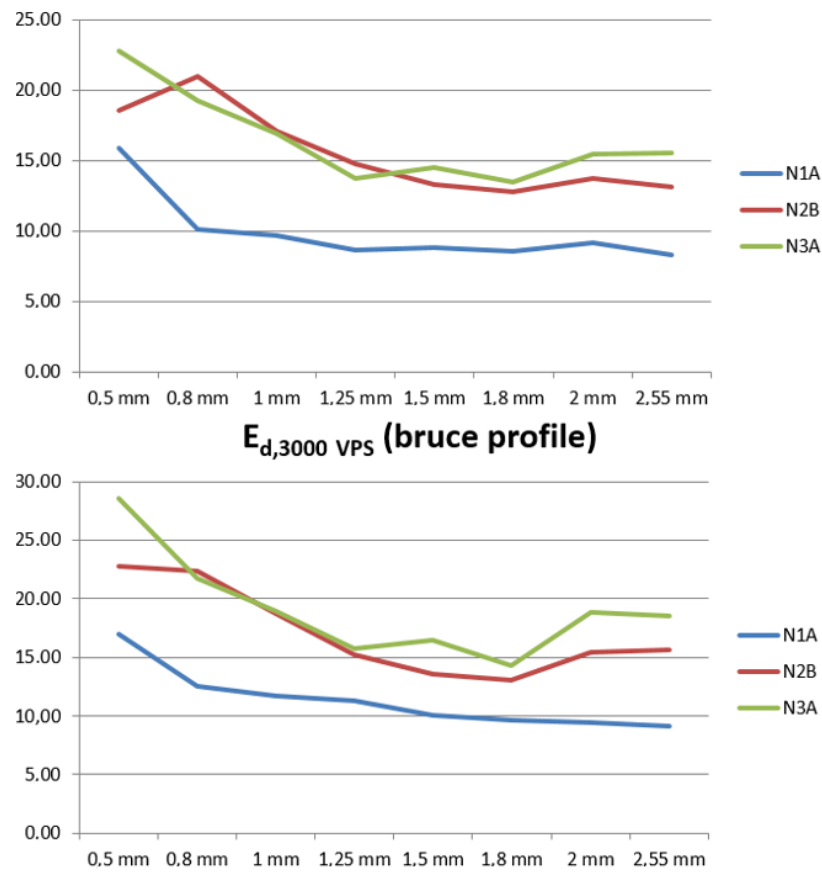

Fig. 3. Comparison of the dielectric strengths of the 3 oils with respect to $500 / 2000 / 3000$ Vps for flat and Bruce profile type electrodes.

The next phase of the tests was the inspection of the effect of relaxation time on dielectric strength. This was achieved by using the flat electrodes cell filled by N2B oil. It was used a voltage rate of $500 \mathrm{Vps}$ and gaps of 2/1/0.5 mm (Fig. 4).

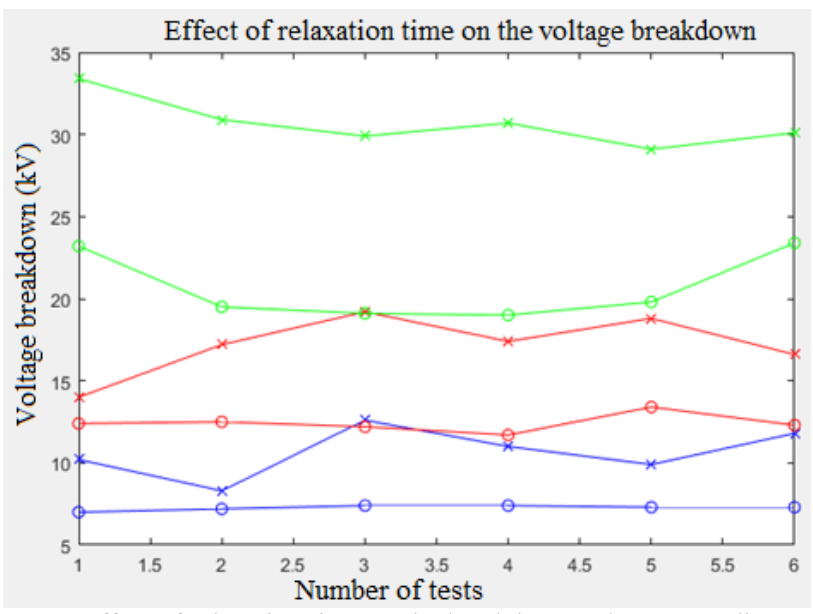

Fig. 4. Effect of relaxation time on the breakdown voltage according to the standards (o) and according to the new times (x), $0.5 \mathrm{~mm}$ marked with blue, $1 \mathrm{~mm}$ marked with red and $2 \mathrm{~mm}$ marked with green.

\section{Testing setup-simulation}

The device plugs on AC supply $230 \mathrm{~V} / 50 \mathrm{~Hz}$. A circuit breaker is responsible for power interruption when the current increases instantly to high values at the moment of breakdown. Afterwards follows the stair of autotransformer which has a moving indicator in order to receive all the values between $0-230 \mathrm{~V}$.

Fig. 5 shows the test transformer used to generate the required $\mathrm{AC}$ voltage. The applied $\mathrm{AC}$ voltage was measured using a capacitance divider (Fig. 6).

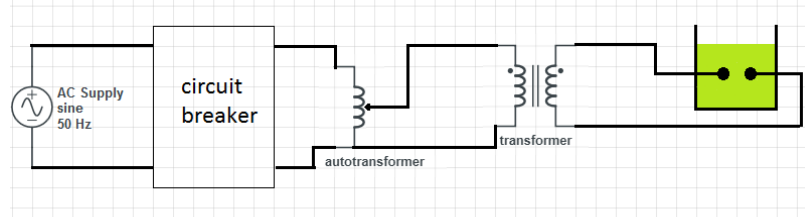

Fig. 5. Experimental device electrical circuit simulation.

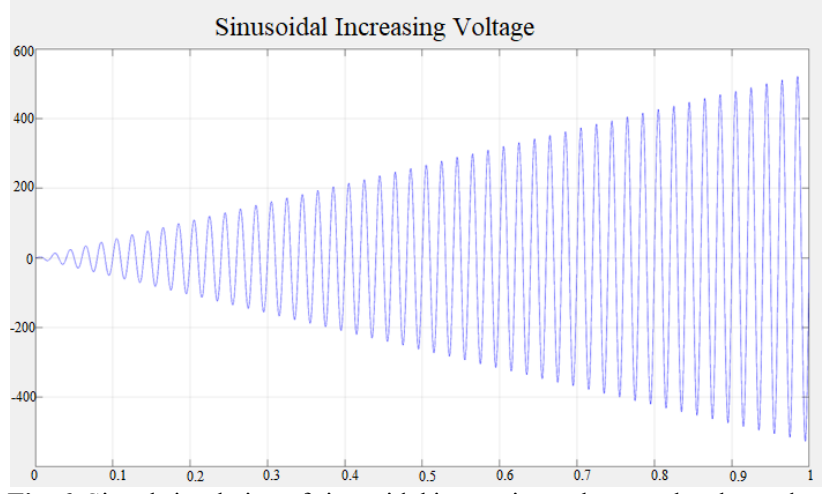

Fig. 6. Signal simulation of sinusoidal increasing voltage at the electrodes at $500 \mathrm{Vps}$ for $1 \mathrm{sec}$ (Matlab).

The oil gap is simulated by a RC load in parallel. In order to simulate the breakdown of the gap, by which in real conditions the circuit breaker would instantly open due to short circuit current, the breaker was adjusted to open in a real value of voltage breakdown (Fig. 7).
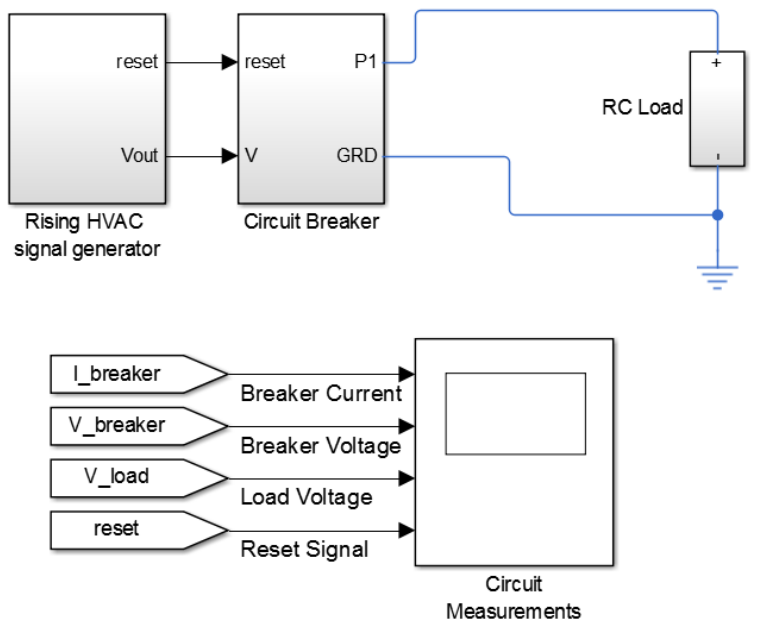

Fig. 7. Circuit simulation (Matlab).

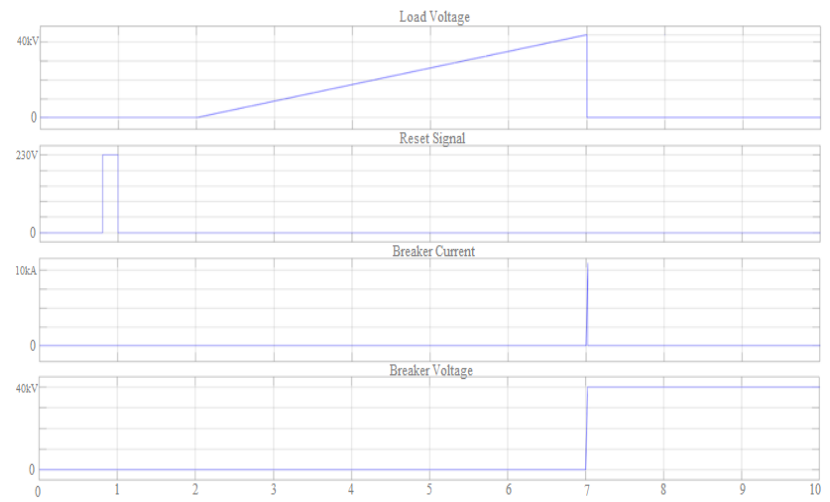

Fig. 8. Signals as shown by scope. Load voltage, reset signal, breaker current and breaker voltage respectively (Matlab). 
In Fig. 8. the load voltage is increased until the breakdown occurs. The circuit breaker current at the moment of the breakdown takes a high value, thus the breaker is activated and the current spike drops to zero. Also, the voltage at the terminals of the breaker increases to the value of voltage applied, until the reset button is pressed and the circuit returns to the original state.

For the electrostatic field calculation Finite Elements Method (FEM) analysis and Finite Difference Method (FDM) as shown below (Figs. 9 and 10 respectively).

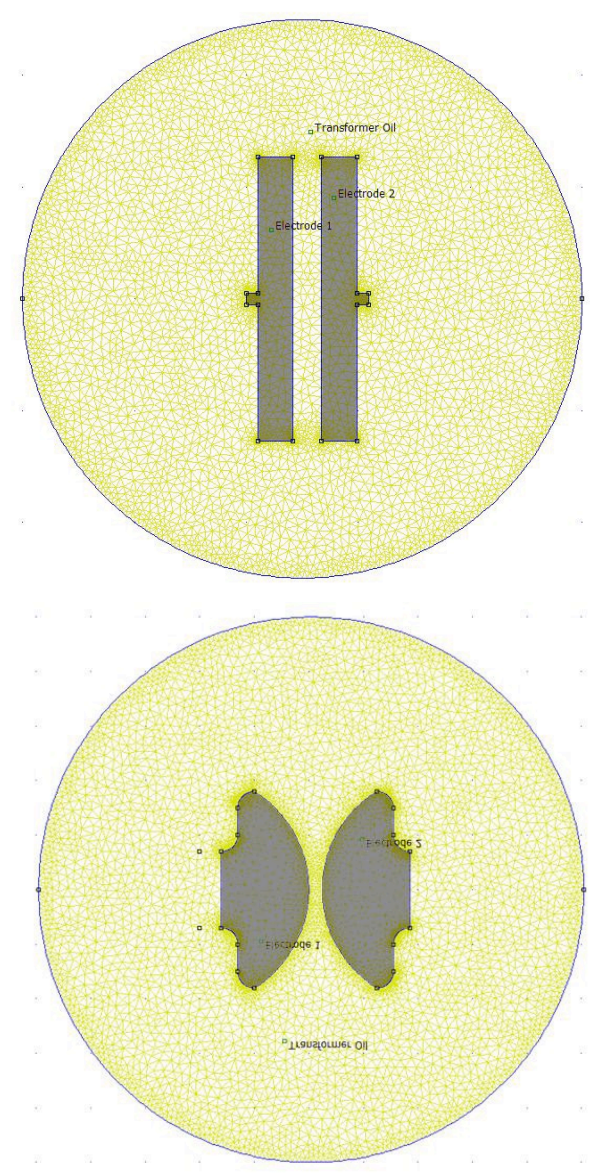

Electric Field Lines, $\mathrm{E}(\mathrm{x}, \mathrm{y})$ in $\mathrm{kV} / \mathrm{mm}$

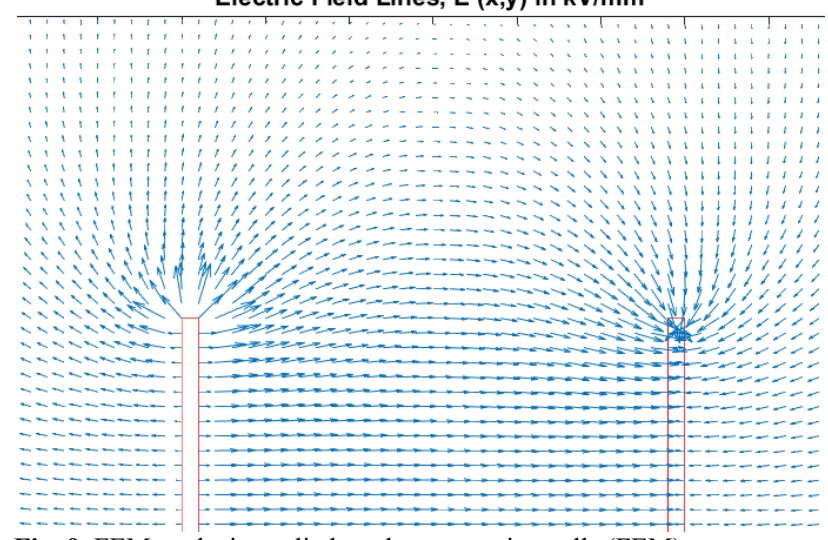

Fig. 9. FEM analysis applied on the two testing cells (FEM)

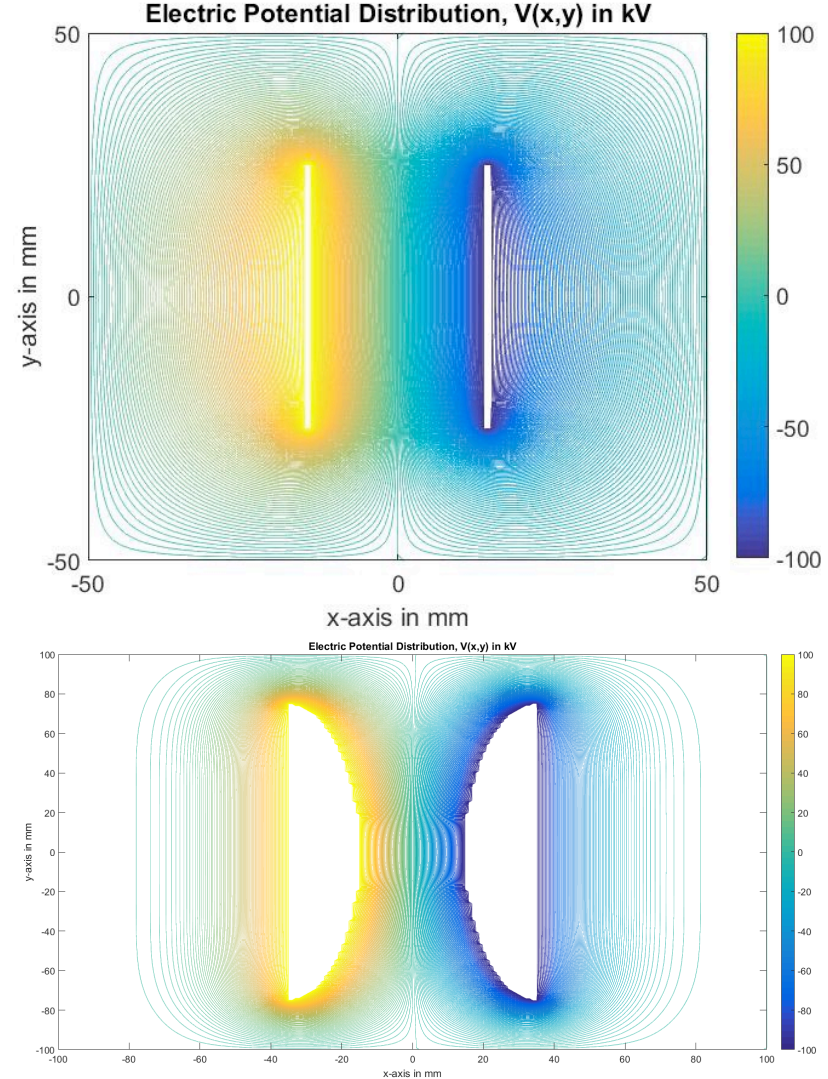

Fig. 10. FDM analysis applied to the test cell with parallel electrodes (Matlab).

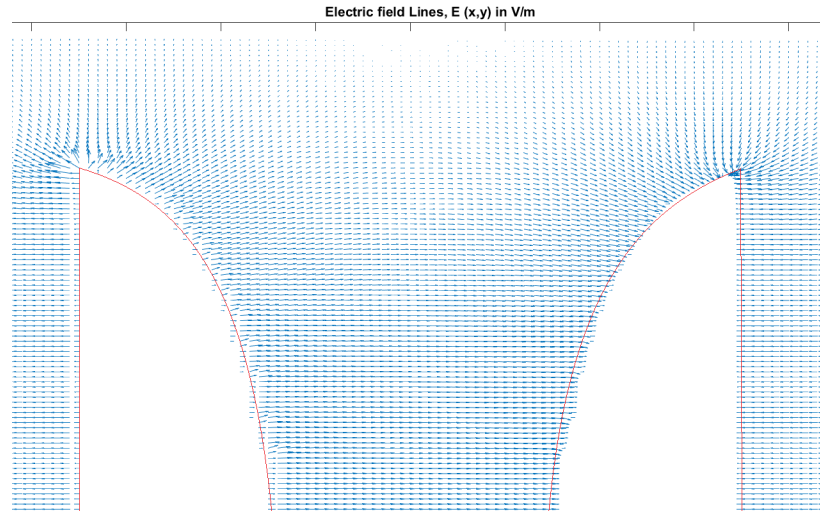

Fig. 11 FDM analysis applied to the Bruce profile test cell (Matlab)

Since no sharp points and/or protrusions were involved, both FEM and FDM seem to be efficient in calculating the electric field distribution of both electrode arrangements (Fig. 9, Fig. 10). It is to be noted that with the Bruce profile electrode arrangement, the electrodes are not as smooth as they are in reality but this depends on how dense the mesh arrangement in the electrode gap [9]. Nevertheless, it is obvious that this arrangement provides uniform electric field distribution (Fig. 11).

\section{Discussion}

This experimental setup is according to ASTM D1816 and ASTM D877 standards and it gives results about the oil suitability for use in power transformers. From the above tests, it can be easily ascertained that the voltage breakdown reduces with gap reduction, it increases with increasing voltage rate, it gives higher dielectric strength values for Bruce profile electrodes and it increases while relaxation time is increased. 
Additionally, as the gap decreases the difference between the means of the breakdown voltage for a given gap decreases. Namely, the graphs for a small gap converge at one point. Increasing the gap length has as consequence the reduction of dielectric strength. This is understandable since a bigger gap implies larger oil volume under electric stress and thus the existence of various factors influencing the breakdown [10, 11]. The increasing voltage rate affects positively the dielectric strength of transformer oil since this means the higher rate of rise of voltage application gives lesser time to foreign matter and/or bubbles to align in order to establish bridges between the electrodes [12]. On the other hand, it should be remembered that the effect of voltage duration also depends on the quality of the tested oil [13]. Higher dielectric strength of oil results with the Bruce profile electrodes may be attributed to the rounding of their edges in contradistinction to the flat electrode arrangement $[14,15]$. The relaxation time between measurements affects the dielectric strength of the oil. Short settling time does not allow either the bubbles from the previous breakdown to be dissolved or the decomposition particles to settle under the influence of gravity. Consequently, there may be more "weak links' in the actual bulk of the oil [16].

During the tests it was observed that the voltage breakdown increased with the renewal of the sample. Such an increase is due to the absence (or removal) of micro-bubbles produced during the repeated breakdowns of the oil and/or of impurities. Moreover, decomposition products have a greater density in a gap under stress than in the rest of the oil and this effect may influence to a more significant extent the small gaps [17].
Furthermore, in view of older and more recent research, besides the aforementioned uniform electrode arrangements, non-uniform electrode systems may be used in order to identify non-uniform electric field breakdown effects [18-20]. Such an effort will further elucidate the mechanisms of breakdown in transformer oil together with an effort to better design oil insulation systems [21,22].

\section{Conclusions}

In the present work, some results regarding the dielectric strength of three different transformer oils are presented. It seems that with a typical Foster test cell, Bruce profile electrodes give slightly higher dielectric strength results than the flat electrodes. FEM and FDM analysis of electrode gap reveals that both method provides have similar results and Bruce electrode have uniform field without any field enhancement. Increasing voltage rates seem to have influence on the dielectric strength of transformer oil. Lastly, the relaxation time between measurements have high influence on the dielectric strength of transformer oil. In conclusion, it is evident that - following the standards IEC 60156 and IEC 60422 - the Foster test cell and the respective electrode arrangements can well distinguish various transformer oil qualities.

This is an Open Access article distributed under the terms of the Creative Commons Attribution License.

\section{References}

1. D. F. Blair, "Breakdown in liquids", pp. 15-32, in the book "Electruical Insulation", edited by A. Bradwell, Eds. Peter Peregrinus Ltd., London, UK, 1983.

2. F. D. Waddington, "Properties and applications of liquid insulants", pp. 114-130, in the book "Electrical Insulation", edited by A. Bradwell, Eds. Peter Peregrinus Ltd., London, UK, 1983.

3. A. H. Sharbaugh, J. C. Devins, S. J. Rzad, "Progress in the field of electric breakdown in dielectric liquids", IEEE Transactions on Electrical Insulation, Vol. 13, No. 4, pp. 249-276, 1978.

4. D. Kind, H. Kaerner, "High-Voltage Insulation Technology", Book, Eds. Friedr. Vieweg \& Sohn, Braunscheig, Germany, 1985.

5. R. Badent, "Modell der elektronendominanten Streamerentladung in Isolieroel", $\mathrm{Ph}$. D. Thesis, Institut fuer Elektroenergiesysteme und Hoch-Spanningstechnik (IEH), Universitaet Karlsruhe, Germany, 1996.

6. A. Beroual, M. Zahn, R. Badent, K. Kist, A. J. Schwab, H Yamashita, K. Yamazawa, M. Danikas, W. G. Chadband and Y. Torshin, "Propagation and structure of streamers in liquid dielectrics", IEEE Electrical Insulation Magazine, Vol. 14, No. 2, pp. 6-17, 1998 .

7. M. G. Danikas, "Breakdown of transformer oil", IEEE Electrical Insulation Magazine, Vol. 6, No. 5, pp. 27-34, 1990.

8. IEC 60156-1995 standard on: Insulating liquids - Test method of determination of the breakdown voltage at power frequency.

9. E. Kuffel, W. S. Zaengl, J. Kuffel, "High Voltage Engineering: Fundamentals", Eds. Newness (Butterworth-Heinemann), Oxford, 2000.

10. M. G. Danikas, "Factors affecting the breakdown strength of transformer oil", M. Sc. Thesis, University of Newcastle-upon-Tyne, Department of Electrical and Electronic Engineering, 1982.

11. M. G. Danikas, R. Sarathi, G. E. Vardakis, S. Morsalin, "Dealing with the size effect in insulating liquids: A volume effect, an area effect or even a particle effect?", Engineering, Technology \& Applied Science Research, Vol. 10, No. 5, pp. 6231-6236, 2020.

12. M. G. Danikas, R. Sarathi, S. Morsalin, "A short review of some of the factors affecting the breakdown strength of insulating oil for power transformers", Engineering, Technology \& Applied Research, Vol. 10, No. 3, pp. 5742-5747, 2020.

13. T. J. Gallagher, "Simple Dielectric Liquids: Mobility, Conduction, and Breakdown, Eds. Clarendon Press, Oxford, UK, 1975.

14. P. Felsenthal and B. Vonnegut, "Enhanced charge transfer in dielectric fluids containing conducting particles," British Journal of Applied Physics, Vol. 18, pp. 1801-1806, 1967.

15. G. Molinari, A. Viviani, "Analysis of charge exchange mechanism between impurities and electrodes in a dielectric liquid", Journal of Electrostatics, Vol. 7, pp. 27-32, 1979.

16. W. R. Bell, M. G. Danikas, "Factors affecting the breakdown strength of transformer oil", Conference Record of 1982 IEEE International Symposium on Electrical Insulation, June 7-9, 1982, Philadelphia, Pa., USA, pp. 264-267.

17. W. R. Bell, "Influence of specimen size on the dielectric strength of transformer oil", IEEE Transactions on Electrical Insulation, Vol. 12, No. 4, pp. 281-292, 1977.

18. R. Badent, "Modell der elektronendominanten Steamerentladung in Isolieroel", $\mathrm{Ph}$. D. Thesis, Universitaet Karlsruhe, Institut fuer Elektroenergiesysteme und Hochspannungstechnik (IEH), 1996

19. Md. Ashiquzzaman, S. Mitra, N. Md. Molla, T. Chakma, K. F. Nasrin, "Testing of dielectric strength of transformer oil, insulation paper and corona effect wire", Proceedings of 2020 IEEE Region 10 Symposium (TENSYMP), 5-7 June, 2020, Dhaka, Bangladesh, pp. 1026-1029.

20. I. O. Muravlev, M. A. Surkov, E. V. Tarasov, Kh. Tsoggerel, N. F. Uvarov, "Transformer oil dielectric strength in the contact gap of the explosive arc-extinguishing device", Proceedings of the $5^{\text {th }}$ International Conference: Modern Technologies for Non-Destructive Testing, IOP Conf. Sesries: Materials Science and Engineering, Vol. 189, 2017, 6 pages.

21. M. G. Danikas, "Bubbles in insulating liquids: A short review", Engineering, Technology \& Applied Science Research, Vol. 9, No. 6, pp. 4870-4875, 2019.

22. J. K. Nelson, "An assessment of the physical basis for the application of design criteria to dielectric structures", IEEE Transactions on Electrical Insulation, Vol. 24, pp. 835-847, 1989. 